\title{
FUZZY MODELING OF CYANOBACTERIAL SURFACE WATERBLOOMS: VALIDATION WITH NOAA-AVHRR SATELLITE IMAGES
}

\author{
Bas W. Ibelings,,${ }^{1,2,5}$ Marijke Vonk, ${ }^{3,4}$ Hans F. J. Los,${ }^{3}$ Diederik T. van der Molen, ${ }^{1}$ \\ AND WOLF M. MoOIJ ${ }^{2}$ \\ ${ }^{1}$ Institute for Inland Water Management and Waste Water Treatment (RIZA), P.O. Box 17, NL 8200 AA, \\ Lelystad, The Netherlands \\ ${ }^{2}$ Netherlands Institute of Ecology, Centre for Limnology (NIOO-KNAW-CL), Department of Foodweb Studies, \\ Rijksstraatweg 6, NL 3631 AC, Nieuwersluis, The Netherlands \\ ${ }^{3}$ WL Delft Hydraulics, P.O. Box 177, NL 2600 MH, Delft, The Netherlands \\ ${ }^{4}$ National Institute of Public Health and the Environment (RIVM), P.O. Box 1, NL 3270 BA, Bilthoven, The Netherlands
}

\begin{abstract}
Surface waterblooms of toxic cyanobacteria (scums) interfere with the use of lakes, for instance in the production of drinking water or for recreation. Routine monitoring data are not sufficient for early warning due to the large temporal and spatial variability in the occurrence of surface waterblooms, and the time lag between the formation of the scum and the availability of relevant information for risk management. We combined a "traditional" dynamic simulation model based upon differential equations with fuzzy logic to describe the three main conditions governing surface waterbloom formation: (1) a preexisting population of cyanobacteria, (2) buoyancy of the cells, and (3) stability of the water column. The attributes and membership functions of the fuzzy model were based on earlier field studies of diel changes in buoyancy and vertical distribution of cyanobacteria. The model was applied without further calibration to the large lake IJsselmeer $\left(1200 \mathrm{~km}^{2}\right)$ in the Netherlands, and we validated the model output using 12 years of NOAA-AVHRR (National Oceanic and Atmospheric Administration-Advanced Very High Resolution Radiometers) satellite images on which surface blooms are discernible as an enhanced vegetation index or increased surface water temperature. Existing surface blooms were predicted with high accuracy, but additional blooms were also predicted. A statistical test (Cohen's Kappa) showed that correct predictions of the absence or presence of surface blooms were highly unlikely to have occurred by chance only. The model can be used to predict the occurrence of surface waterblooms in advance on the basis of the long-term weather forecast, leaving time for appropriate management of the problem. The lake management has expressed interest in converting the present model into a fully operationalonline-early warning system.
\end{abstract}

Key words: algal blooms, early warning; blue-green algae; cyanobacteria; ecological models; eutrophication; fuzzy logic; Microcystis; remote sensing; scums; water management.

\section{INTRODUCTION}

Cyanobacteria in general, and surface waterblooms in particular, are a serious problem in water management (e.g., Paerl 1988). During surface waterbloom formation, a population of buoyant cyanobacteria accumulates in a distinct scum at the lake surface, in the absence of wind mixing. Surface waterblooms are not aesthetic and give a foul smell. No phenomenon leaves such a lasting impression of eutrophication of inland waters as these dense blue-green scums. Most importantly perhaps, the (potentially) toxic biomass of cyanobacteria is concentrated manifold in these surface blooms. Buoyancy is at the heart of the "toxic blue-

Manuscript received December 3 2001; revised 19 December 2002; accepted 5 February 2003. Corresponding Editor: C. A. Wessman.

${ }^{5}$ Present address: Netherlands Institute of Ecology, Centre for Limnology (NIOO-KNAW), Department of Foodweb Studies, Rijksstraatweg 6, NL 3631 AC, Nieuwersluis, The Netherlands. green algae" problem. If the cyanobacteria did not float they would not accumulate, and the risk of swallowing a dangerous amount of toxin would be much reduced. Guidelines by the World Health Organization (Chorus et al. 2000) take scum formation as a specific risk factor into account. In this paper, we only discuss the phenomenon of surface water bloom formation (scums), not cyanobacterial blooms in general.

The conditions for surface waterbloom formation are seemingly simple: (1) the preexistence of a population of cyanobacteria; (2) buoyant cells, and (3) stability of the water column (Reynolds and Walsby 1975). Surface waterbloom formation is a phenomenon that operates on a time scale of hours. Often they form overnight. The short windows that commonly exist between mixing events (e.g., Ibelings et al. 1991) indicate that it is really a preexisting population of cyanobacteria that accumulates at the surface, rather than surface blooms resulting from growth at the lake surface. Buoyancy is provided by intracellular gas vacuoles, made up of many gas vesicles, hollow structures filled with air (see 
Walsby 1994 for a review). In the light, cyanobacteria store carbohydrates from photosynthesis as glycogen and this acts as a ballast component. When the amount of ballast exceeds the flotation provided by gas vacuoles the cells sink. In deeper, darker layers, the cells respire the stored glycogen and regain buoyancy. This cycle leads to a diel pattern in the percentage of floating colonies, a level that may approach $100 \%$ in the early morning (Ibelings et al. 1991). A fully buoyant population does not necessarily lead to surface blooms. Even low-to-moderate wind speeds may prevent upward vertical migration of the buoyant colonies. The wind induced shear velocity in surface layers easily exceeds the flotation velocity of buoyant cyanobacteria (Reynolds 1987). Stability of the water column in freshwater is the result of heating of the lake surface (by the sun) prevailing over wind induced mixing. Hence surface blooms are only expected during periods of low wind speed and/or high insolation.

Buoyancy as a requirement for cyanobacteria like Microcystis to develop into large populations is well supported by models (Sherman and Webster 1994, Howard 2001), experimental data (Ibelings et al. 1994, Huisman et al. 1999), and field studies (Ibelings et al. 1991, Visser et al. 1996). According to the work by Huisman et al. (1999), Microcystis is not a strong competitor in a well-mixed environment on basis of its inferior critical light intensity. At low mixing rates, however, Microcystis is able to outcompete others because the cyanobacterium obtains a superior position in the underwater light gradient. This autonomous repositioning in the water column has been described as "tracking the mixed layer" by Humphries and Lyne (1988). Walsby et al. (1997) showed that buoyancy in a population of Aphanizomenon in the Baltic increased net photosynthesis twofold during periods of alternate mixing and stability. The daily integral of photosynthesis in buoyant populations of Anabaena circinalis was five times as high as in evenly distributed cyanobacteria (Mitrovic et al. 2001).

The aim of the research documented in this paper was to design and test an early warning system that predicts the occurrence of cyanobacterial surface waterblooms (scums), in particular in large lakes. In such lakes, reliable monitoring of harmful algal blooms is problematical, especially using traditional methods like in situ sampling, but even with state-of-the-art techniques such as remote sensing (cf. Schofield et al. 1999). Both techniques are not suitable for early warning due to the time lag between the occurrence of waterblooms and the availability of the monitoring data. To circumvent the time lag problem, we used a modeling approach based on long-term weather forecasts to predict surface waterbloom formation well in advance. We choose the innovative approach of combining "traditional" numerical modeling based on differential equations with an expert system based on fuzzy logic.
The concept of fuzzy logic was introduced by Zadeh as an extension of Boolean logic (Von Altrock 1995). In fuzzy logic the state variables are expressed in terms of an ordered set of qualifications such as "low," "intermediate," or "high." But instead of assigning a single qualification to a state variable (i.e., the current state is "high"), fuzzy logic applies the concept of memberships to multiple qualifications. For instance, a state variable could be assigned a membership of 0.25 to the qualification "intermediate" and a membership of 0.75 to the qualification "high." As a result, multiple rules of the expert system are applied in parallel, each with their own weight. Note that memberships do not represent probabilities. From a probabilistic point of view, the state would either be low or intermediate, but with uncertainty as to which state. In the membership representation, the state is both low and intermediate (each to a certain degree). It is obvious that this format allows for a more continuous representation of the state variables, as would be the case for a numerical variable, while still representing the variable in qualitative terms, as would be the case in Boolean logic. Because the information is stored in qualitative terms we can implement in the model the abundant qualitative knowledge about bloom formation available among experts. It is often impossible to translate such knowledge in terms of the mathematical expressions needed for a model based on differential equations. For a more detailed documentation of the possibilities and application of fuzzy logic, the reader is referred to a special issue of Ecological Modeling, Volume 85 (1996).

\section{Methods}

We apply fuzzy logic to transfer numerical information on algal biomass, wind speed, irradiance, and time of the day into a prediction of the occurrence of surface blooms. Algal biomass is obtained from an established water quality model based on differential equations while wind speed and irradiance are obtained from meteorological monitoring stations. Data on wind speed, irradiance, and time of the day are translated to memberships of sets in qualitative terms, in a process called fuzzyfication. A qualitative prediction of the degree of appearance of algal surface blooms is derived in two steps of logical inference (fuzzy inference): (1) from wind speed, irradiance, and time of the day to stability of the water column and buoyancy of the cells, and (2) from stability and buoyancy to the appearance of algal blooms. This qualitative prediction of the degree of appearance of algal blooms is translated into a numerical representation in a final step called defuzzyfication. The final prediction of an algal surface bloom is made by combining this latter number with the algal biomass as predicted by the water quality model. To apply the model in a spatial context we extended it with a simple particle-tracking model that describes the transport of existing scums across the lake. We applied the model to the large lake IJsselmeer 

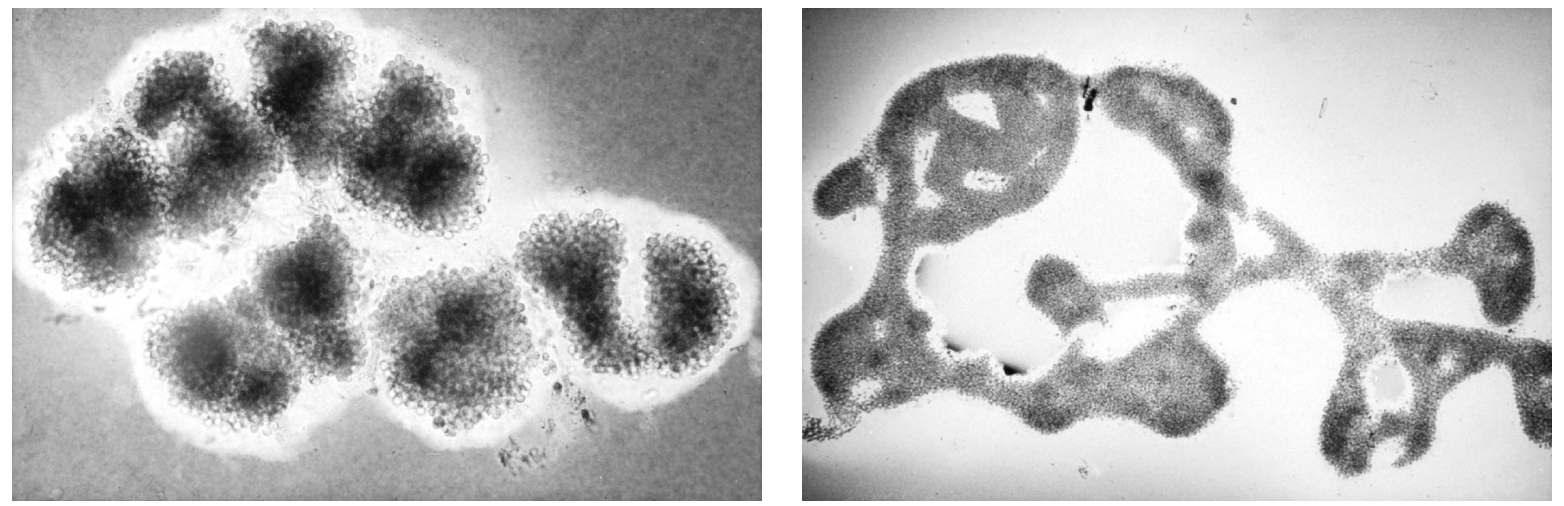

Plate 1. Two colonies of different species of cynobacterium belonging to the genus Microcystis taken from a surface bloom on Lake Ijsselmeer, The Netherlands. Many individual cells can be seen embedded in a common layer of mucilage $(100 \times$ magnification, stained with India ink). Photograph by B. W. Ibelings.

in the Netherlands (see Fig. 1), and validated the model using NOAA-AVHRR images. Fig. 2 presents an overview of the model structure.

\section{Model component 1-cyanobacterial biomass}

The integrated hydrological, water quality, and algal growth model WAQUA-DBS (Delwaq-Bloom-Switch) was used to calculate the cyanobacterial biomass in the IJsselmeer. The two-dimensional model WAQUA models the hydrodynamics of the IJsselmeer, using a time step of 10 minutes and up-to-date values on wind forcing. The model is described extensively by Stelling (1984), and used, among others, by Middelkoop and van der Perk (1998). Delwaq calculates transport of substances as a function of advective and dispersive transport. Bloom, the algal module in DBS, distinguishes between green algae, diatoms, and cyanobacteria. In the latter group, a further distinction into several ecotypes is made, exemplified by colonial cyanobacteria like Microcystis (see Plate 1), $\mathrm{N}_{2}$-fixers like Aphanizomenon, and filamentous species like Planktothrix. Sediment processes like the release of phosphorous are included, but grazing is applied as a forcing function. The light climate is modeled according to Buiteveld (1995) and integrated in DBS. The algal growth model uses a variable time step depending on the process rates. The variables governing algal growth were calculated after aggregation of the more detailed

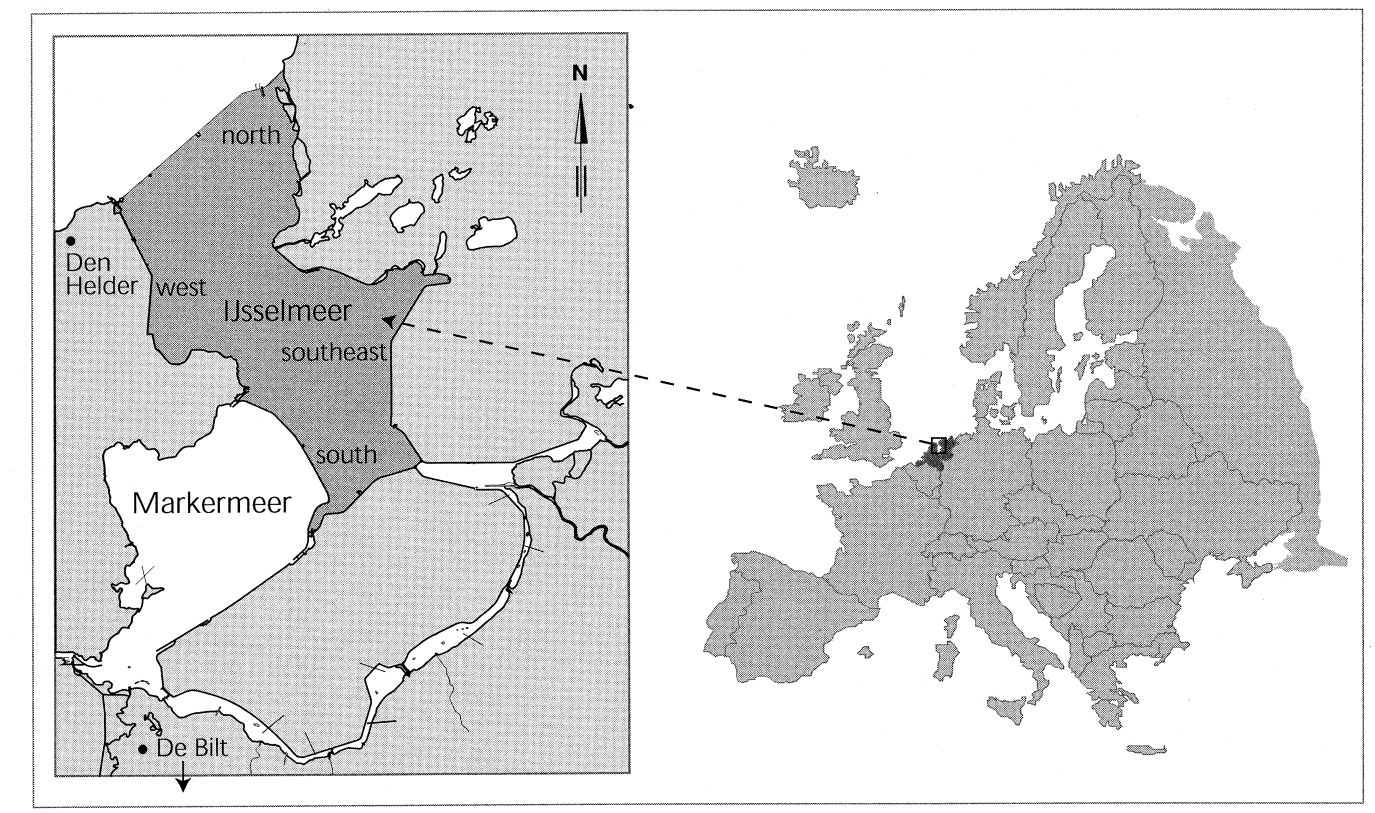

FIG. 1. Map of the IJsselmeer area in the Netherlands (Western Europe), including the location of meteorological stations and four geographical areas distinguished in the model output shown in Fig. 7. 

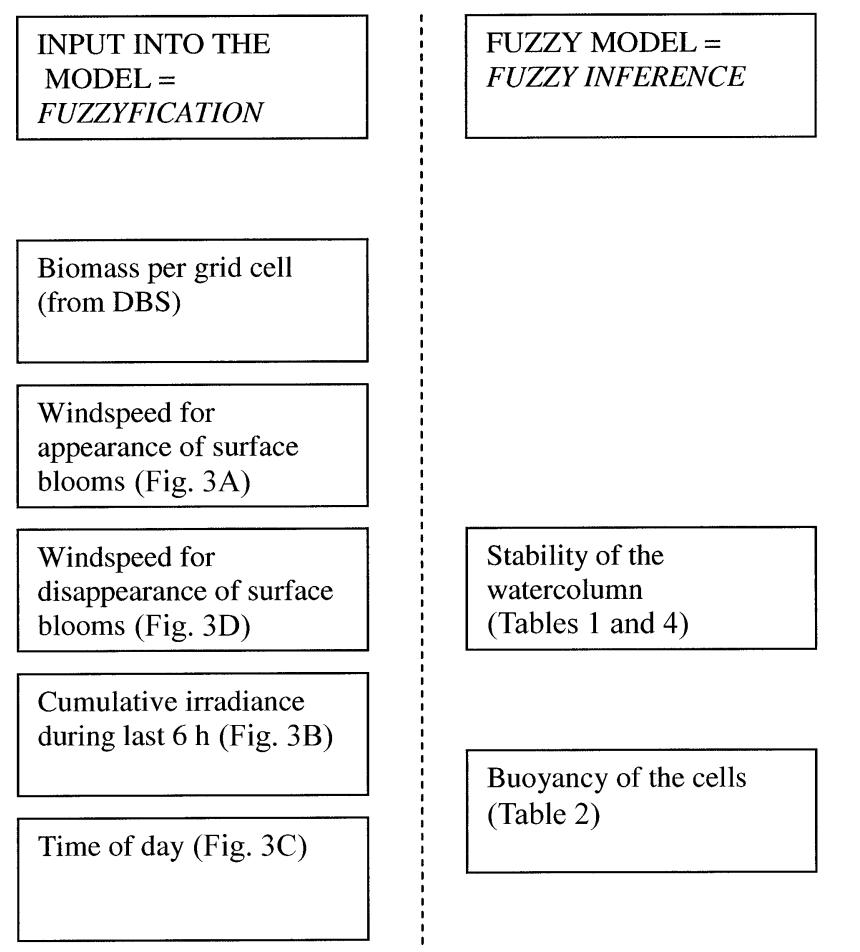

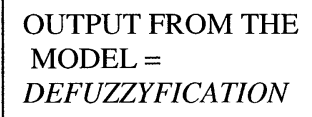

Degree to which surface

blooms (dis)appear

(Tables 3 and 5)

FIG. 2. Schematic representation of fuzzy model describing the (dis)appearance of surface waterblooms. The model output describes the degree to which surface waterblooms (dis)appear per model grid cell. Surface waterbloom formation is dependent on biomass (from DBS), water column stability, and buoyant cells. The latter two conditions are computed using a fuzzy model. The disappearance of existing surface blooms is solely dependent on a breakdown of water column stability. Input into the fuzzy model is shown on the left: data on wind speed and irradiance are translated into memberships of sets of qualitative descriptions, using expert knowledge on bloom formation (see Fig. 3A-D for memberships). This first step is called fuzzyfication. In the second step, stability and buoyancy are computed in qualitative terms (see Tables 1 and 2) on basis of the memberships defined earlier. This second step, called fuzzy inference, builds an expert system based upon a set of IF-THEN rules. In a third and final step (called defuzzyfication), the qualitative model output (e.g., surface blooms will form to a high degree; see Tables 3 and 4) is translated into a quantitative value. The coefficients used in defuzzyfication are shown in Table 5. The whole process enables the combination of quantitative and qualitative data into one model and allows access to expert knowledge that would otherwise remain unused.

hydrological schematization of $1 \times 1 \mathrm{~km}$ into 85 grid cells.

Detailed modeling of the IJsselmeer using DBS was performed for 1988-1989 in an earlier study (Lammens 1999). This study included calibration and validation of the model for the IJsselmeer, in which chloride, chlorophyll $a$, and nutrients were tuned successively. Three types of parameters were distinguished in the calibration procedure: (1) fixed, system-independent parameters, mainly taken from the literature; (2) fixed, system-dependent parameters, which vary only with the selection of certain model variables such as an algal species; and (3) variable, system-dependent parameters. The DBS model shows specific sensitivity to some of the variables in this latter group, which can be used as calibration coefficients. Algal growth in the IJsselmeer is especially sensitive to variation in the underwater light climate; nutrients are hardly ever limiting for growth in this hypertrophic system. Under the fully mixed conditions in the model algal growth is restricted to the more shallow parts of the lake (3-4 m), whereas no net growth occurs in deeper parts $(5-6 \mathrm{~m})$. Input data for the phosphorus loading in our period of study (1983-1994) were derived from the 1988-1989 model (Lammens 1999) using a regression with the phosphorus concentration in the main tribute, the river IJssel (branch of the Rhine River), for which monthly estimates were available. For other inputs, the averaged data of 1988-1989 were used, also for the grazing by zooplankton and zebra mussels, as no further detailed information was available. Up-to-date records were used for the water temperature, wind speed, and irradiation. Our period of study covers 1983-1994, based among other things on the availability of satellite images for validation of the model. We refer to earlier publications by Van der Molen et al. (1994) and Van der Molen (1999) for a more detailed description of DBS.

\section{Model component 2-buoyancy and stability of the water column}

Buoyancy and water column stability were modeled using a fuzzy logic expert system. In the fuzzy module, 
a distinction is made in factors describing the appearance and subsequent disappearance of surface blooms. The attributes (low, intermediate, etc.) and membership functions are based upon expert knowledge, which was derived especially from field studies on the diel variation in buoyancy and vertical distribution of cyanobacteria in the Dutch Vinkeveen lakes (Ibelings et al. 1991). Data from the Nieuwe Meer (Visser et al. 1996) and observations on Esthwaite Water (Ibelings and Maberly 1998) and Windermere (Walsby et al. 1991) in the English Lake District were also used. For appearance of blooms, the mean wind speed during the last hour $(\mathrm{m} / \mathrm{s})$, the cumulative flux of solar irradiance over the past $6 \mathrm{~h}\left(\mathrm{~J} \cdot \mathrm{cm}^{-2} \cdot 6 \mathrm{~h}^{-1}\right)$, and the time of day were taken into account (see Fig. 2 for a schematized structure of the model). Wind speed and cumulative irradiance determine the stability of the water column; buoyancy is determined by irradiance (the percentage of sinking cells on overcast days is only limited) and the time of day (see Ibelings et al. 1991). Disappearance of existing surface blooms is considered to be instantaneous and solely dependent on a breakdown of water column stability (see legend of Fig. 2). Meteorological data were obtained and averaged for two stations around the perimeter of the IJsselmeer (Den Helder and De Bilt stations) (see Fig. 1).

Expert knowledge about buoyancy and stability of the water column is formalized in three steps known as fuzzyfication, fuzzy inference, and defuzzyfication. In the first step (fuzzyfication), so-called membership functions are defined for the input variables and applied to their actual values, for instance the data on wind speed. Based upon expert knowledge, a wind speed of $2 \mathrm{~m} / \mathrm{s}$ is allocated $50 \%$ to membership in "low wind speed," and $50 \%$ to "moderate wind speed." Fig. 3 shows all the membership functions developed for the model. It is the key procedure in which qualitative expert knowledge is quantitatively made available for the model. In the second step (fuzzy inference), an expert system is laid down in a set of rules consisting of a premise and a conclusion, such as "IF wind speed is low AND insolation is high THEN the stability of the water column is high." Tables $1-4$ give an overview of the expert rules that define the model. In a final, third step (defuzzyfication), the qualitative output from the model, in our case, for instance, "scum formation is highly unlikely," is translated into a quantitative but relative value for each hour (see Table 5 for coefficients used in defuzzyfication). The fuzzy module as a whole produces the degree (expressed as a percentage) to which surface blooms appear or disappear in each grid cell of the model. Finally the output of the algal growth simulation model (biomass) and the fuzzy part (degree to which surface blooms appear or disappear) is combined with the mean depth of the grid cell and a mean cyanobacterial flotation velocity of 10 $\mathrm{m} / \mathrm{d}$ to yield, on an hourly basis, the amount of biomass (in $\mathrm{g} \mathrm{C} / \mathrm{m}^{2}$ ) per grid cell, present in surface blooms and/ or suspended in the water column. When the concentration in the surface layer exceeds $10 \mathrm{~g} \mathrm{C} / \mathrm{m}^{2}$, a surface bloom is assumed to be present.

In short, we have parameterized the model in the membership functions using expert knowledge, based upon field observations in smaller Dutch lakes. We have applied the model directly to the IJsselmeer, without further calibration, and validated the model using NOAA images from the IJsselmeer, on which surface blooms are discernable (see Validation). In a sensitivity analysis the degree of the appearance or disappearance of surface blooms was modeled as a function of wind speed (which was varied between 1 and $6 \mathrm{~m} / \mathrm{s}$ at 0.5 $\mathrm{m} / \mathrm{s}$ intervals), cumulative irradiance (varied between 100 and $2000 \mathrm{~J} \cdot \mathrm{m}^{-2} \cdot 6 \mathrm{~h}^{-1}$ at $100 \mathrm{~J} \cdot \mathrm{m}^{-2} \cdot 6 \mathrm{~h}^{-1}$ intervals), and time of day $(\mathrm{h})$.

\section{Model component 3-movement of blooms}

Horizontal transport of existing surface blooms across the lake was modeled using a simple particletracking model. The rate of transport was calculated with the wind drift factor $f_{\text {drift }}=v_{\text {surface }} / v_{\text {wind }}$, where $v$ is the velocity of the surface currents or wind speed respectively. At low-to-moderate wind speed, $f_{\text {drift }}$ equals $1-3 \%$ of this wind speed (Webster and Hutchinson 1994). For the horizontal transport, a $1 \times 1 \mathrm{~km}$ grid of the IJsselmeer was used. If a breakdown of water column stability is predicted, the surface bloom will be re-entrained at its latest location. The algal growth model DBS reassumes calculation of cyanobacterial development in a fully mixed water column.

\section{The lake}

The model was applied to the largest lake in Western Europe, the IJsselmeer. This is a lake that was created in 1932 when a dam sealed off the former (brackish) Zuiderzee from the North Sea. After that, large parts of the lake were reclaimed and in 1976 a second dam separated the IJsselmeer into two parts, resulting in the southern Markermeer and the northern IJsselmeer (Fig. 1). The remaining IJsselmeer is, on average, $4.5 \mathrm{~m}$ deep and has a surface area of $1200 \mathrm{~km}^{2}$. The river IJssel, a branch of the river Rhine, dominates its hydrology. Nutrient concentrations have dropped strongly in the lake (mean concentrations of total phosphorous and nitrogen in the summer half year (April-October) are now 0.12 and $3.2 \mathrm{mg} / \mathrm{L}$, respectively) as a result of decreasing concentrations in the Rhine, but the increase in transparency is still only limited (Van der Molen and Portielje 1994). Transparency is strongly dependent on local conditions, however. In summer, there is usually a sharp gradient from high transparency and low chlorophyll $a$ in the southern half of the lake, to low transparency and high chlorophyll $a$ in the north. This gradient coincides with a reverse gradient in density of zebra mussels (Dreissena polymorpha). The dominating genera of cyanobacteria are Microcystis and Aphanizomenon and these are also mainly (but certainly not 

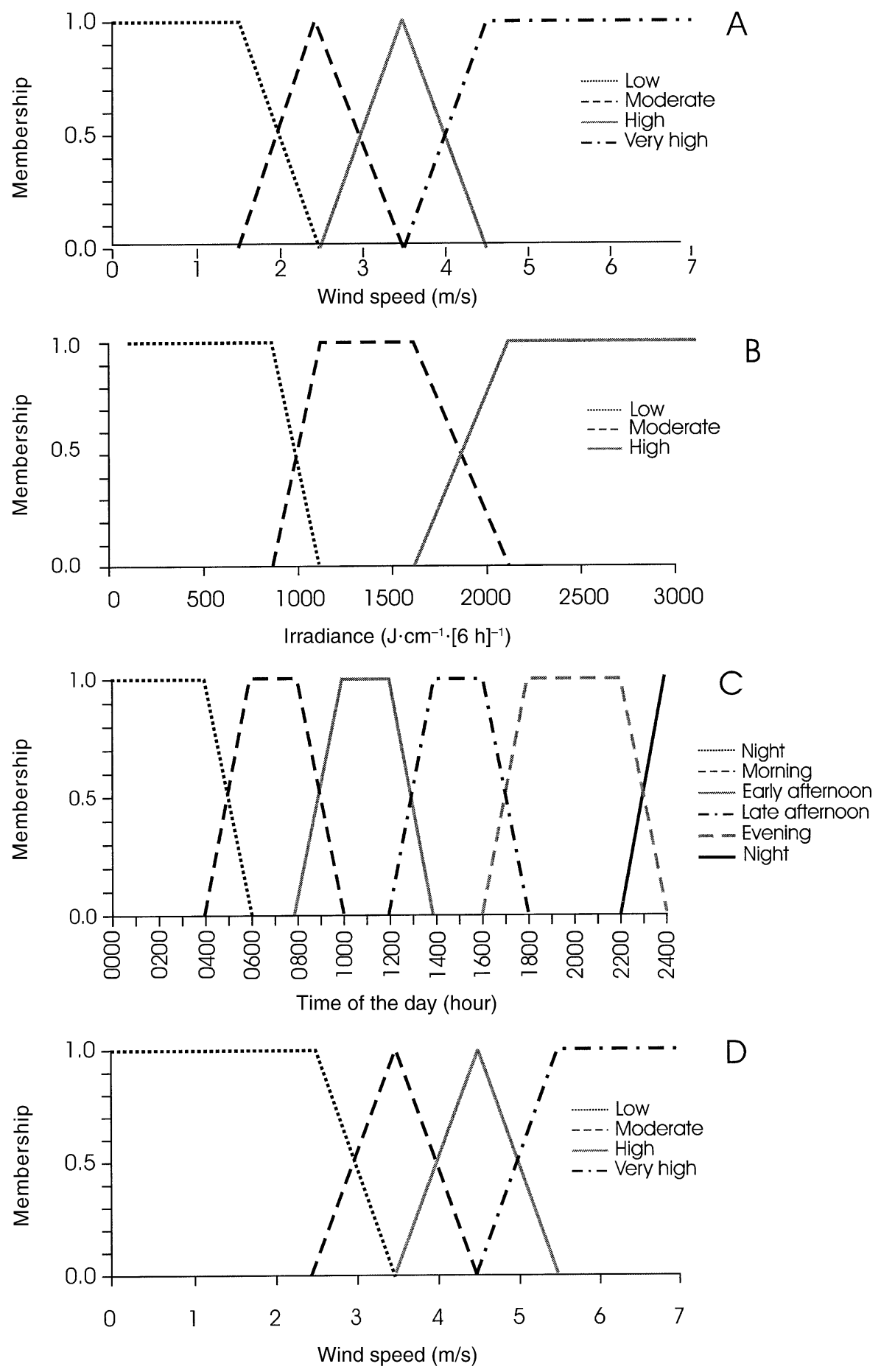

FIG. 3. Membership functions used in the fuzzy logic module governing the appearance of surface blooms: (A) average wind speed during past hour (e.g., a wind speed of $2 \mathrm{~m} / \mathrm{s}$ belongs for $50 \%$ to the class low wind speed and for $50 \%$ to moderate wind speed); (B) cumulative irradiance flux over past $6 \mathrm{~h}$; (C) time of day (related to buoyancy state); (D) membership rule for wind speed governing the disappearance of surface blooms (loss of water column stability).

exclusively) found in the north. Surface blooms of these cyanobacteria may form on an extensive scale, covering hundreds of square kilometers, but smaller local scums have also been observed frequently.

\section{Validation}

The NOAA-AVHRR is a radiation-detection imager that was designed to be used for remotely determining 
TABLE 1. Expert rules used in the fuzzy module regarding the stability of the water column: IF mean wind speed over last hour was moderate AND irradiance flux over last $6 \mathrm{~h}$ was high THEN stability will be high, etc.

\begin{tabular}{lll}
\hline \hline $\begin{array}{c}\text { Mean wind } \\
\text { speed last hour }\end{array}$ & $\begin{array}{c}\text { Irradiance flux } \\
\text { last } 6 \mathrm{~h}\end{array}$ & Stability \\
\hline Very high & high & low \\
Very high & moderate & low \\
Very high & low & low \\
High & high & moderate \\
High & moderate & low \\
High & low & low \\
Moderate & high & high \\
Moderate & moderate & moderate \\
Moderate & low & low \\
Low & high & very high \\
Low & moderate & very high \\
Low & low & high \\
\hline
\end{tabular}

Note: Under conditions of high stability, density gradients in the water column are maintained and resist the impact of (wind induced) mixing on migration of cyanobacteria.

cloud cover and the surface temperature. Data are derived from the five-channel Advanced Very High Resolution Radiometers (AVHRR) on board the NOAA 7, 9, 11, and 14 polar orbiting satellites. Two images per day are available, from the ascending (day) and descending (night) passes. The resolution at nadir is $1 \times$ $1 \mathrm{~km}$. Prangsma and Roozekrans (1989) described the use of NOAA-AVHRR imagery for assessing water quality. AVHRR data are processed by the Royal Netherlands Meteorological Institute (KNMI) using software based on the APOLLO package (UK Meteorological Office). Prangsma and Roozekrans (1989) describe a normalized "vegetation index":

$$
\mathrm{NVI}=\frac{R(0)^{-} \text {channel } 2-R(0)^{-} \text {channel } 1}{R(0)^{-} \text {channel } 2+R(0)^{-} \text {channel } 1}
$$

where $R(0)^{-}$is the subsurface reflectance of light. Channels 1 and 2 are two broad-band channels of 580-

TABLE 2. Expert rules used in the fuzzy module regarding buoyancy. A high buoyancy state implies that colonies are floating because the lift provided by the gas vesicles exceeds (carbohydrate) ballast components in the cells.

\begin{tabular}{lll}
\hline \hline $\begin{array}{c}\text { Irradiance flux } \\
\text { last } 6 \mathrm{~h}\end{array}$ & \multicolumn{1}{c}{ Time of day } & $\begin{array}{c}\text { Buoyancy } \\
\text { state }\end{array}$ \\
\hline High & night & high \\
High & morning & high \\
High & early afternoon & moderate \\
High & late afternoon & low \\
High & evening & moderate \\
Moderate & night & high \\
Moderate & morning & high \\
Moderate & early afternoon & moderate \\
Moderate & late afternoon & moderate \\
Moderate & evening & moderate \\
Low & night & high \\
Low & morning & moderate \\
Low & early afternoon & moderate \\
Low & late afternoon & high \\
Low & evening & \\
\hline
\end{tabular}

TABLE 3. Expert rules used in the fuzzy module regarding the degree of surface bloom formation as a function of the stability of the water column and buoyancy state of the cells.

\begin{tabular}{lll}
\hline \hline Stability & Buoyancy & $\begin{array}{c}\text { Degree of bloom } \\
\text { formation }\end{array}$ \\
\hline Low & high & low \\
Low & moderate & low \\
Low & low & very low \\
Moderate & high & moderate \\
Moderate & moderate & low \\
Moderate & low & low \\
High & high & very high \\
High & moderate & high \\
High & low & moderate \\
Very high & high & very high \\
Very high & moderate & high \\
Very high & low & moderate \\
\hline
\end{tabular}

680 and 725-1100 nm, respectively. Prangsma and Roozekrans used the NVI for detection of surface blooms of cyanobacteria, based on the enhanced nearinfrared reflectance of surface blooms compared to reflectance of "clear water." A positive value of the NVI denotes the presence of surface blooms. Fig. 4 (top panel) shows an example. Moreover, the enhanced absorption of light by surface waterblooms results in heating of the lake surface, and can also be used to trace blooms on AVHRR images (Kahru et al. 1994) (see Fig. 4, bottom panel). The fact that we are only interested in surface waterblooms of cyanobacteria, in which the biomass is concentrated at the lake surface means that the limited vertical resolution of remote sensing is not an issue here. Potentially, 2952 images would have been available in the selected period of study, July through October of 1983-1994 (outside July through October, surface bloom formation is highly unlikely in the IJsselmeer, and perhaps in general, but see Howard [2001] for an opposite view). Just over $10 \%$ of the images (313) turned out to be usable for validation of the model; the remainder were unusable due to the presence of clouds (this highlights the major obstacle for using remote sensing in regions with an

TABLE 4. Expert rules used in the fuzzy module regarding the degree to which surface blooms disappear in response to a breakdown of water column stability.

\begin{tabular}{ll}
\hline \hline Stability & $\begin{array}{c}\text { Degree of bloom } \\
\text { disappearance }\end{array}$ \\
\hline Low & very high \\
Low & very high \\
Mow & very high \\
Low & high \\
Low & high \\
High & low \\
Moderate & moderate \\
Low & moderate \\
Very high & very low \\
Very high & low \\
High & low \\
\hline
\end{tabular}


TABle 5. Coefficients used in defuzzyfication (see Fig. 2 for an overview of the steps involved in constructing the fuzzy model).

\begin{tabular}{cc}
\hline \hline $\begin{array}{c}\text { Degree of surface } \\
\text { bloom appearance } \\
\text { (qualitative) }\end{array}$ & $\begin{array}{c}\text { Degree of surface } \\
\text { bloom appearance (\%) }\end{array}$ \\
\hline Very high & 75 \\
High & 45 \\
Moderate & 20 \\
Low & 9 \\
Very low & 1 \\
\hline
\end{tabular}

Notes: In the final step of the fuzzy model, the qualitative output from fuzzy inference is translated into a "crisp" number by using the coefficients shown in the table. In defuzzyfication, we used the center of maximum (CoM) method (Von Altrock 1995), in which the most typical value for each fuzzy output term is established.

Atlantic climate like The Netherlands). Because of the nature of bloom formation, scums will occur more frequently during periods of warm, stable weather. Hence, it is to be expected that the 313 (largely) cloud free NOAA images still caught a substantial part of the blooms.

\section{RESULTS}

\section{Cyanobacterial biomass-DBS}

The dynamic simulation model DBS correctly reproduced the IJsselmeer gradient in chlorophyll $a$ and transparency (Fig. 5), which is commonly present and is the result of a reverse gradient in the density of zebra mussels. The high filtering capacity of the mussels in the southern part of the lake more than compensates for the optimal growing conditions of the phytoplankton, while lowered densities of the mussels in the northern part permit higher algal biomass, despite less favorable growing conditions. Cyanobacteria dominate the species composition in the northern and western part of the lake with a biomass ranging from 2 to $6 \mathrm{~g}$ $\mathrm{C} / \mathrm{m}^{3}$. In the southern and southeastern part of the IJsselmeer, cyanobacteria were still the dominant group, but with a reduced biomass of $2-3 \mathrm{~g} \mathrm{C} / \mathrm{m}^{3}$. These model outputs correlate reasonably well with field measurements, which indicated only slightly lower values of the algal biomass.

\section{Sensitivity analysis fuzzy model}

The data on cyanobacterial biomass from DBS are combined with fuzzy predictions of water column stability and buoyancy of the cells to yield surface bloom formation. In a sensitivity analysis of the fuzzy model, it was shown that the degree of surface bloom formation decreases rapidly with an increase in wind speed. Scum formation occurs on an extensive scale at a wind speed of $1 \mathrm{~m} / \mathrm{s}$ (given a sufficiently buoyant population), and is nearly absent at wind speeds above $3 \mathrm{~m} / \mathrm{s}$ (Fig. 6A). Furthermore, the degree of surface waterbloom formation (given a sufficiently low wind speed) is maximal between 2400 and 1000 hours and decreases to a minimum at 1500 hours (Fig. 6B). In fact, irradiance has a double effect. On the one hand, high insolation enhances water column stability, which promotes surface waterbloom formation at intermediate wind speeds. On the other hand, high irradiance decreases buoyancy of the cells (when photoinhibition is ignored), reducing the degree to which scums occur. Existing scums stay in position up to wind speeds of $2.5 \mathrm{~m} / \mathrm{s}$; with a further increase in wind speed there is a sharp transition and surface blooms disappear abruptly (Fig. 6C). The effect of insolation on the disappearance of surface blooms is only limited-wind speed is the overriding factor.

\section{Output from the model}

Fig. 7 presents an example of the model output. Shown is the amount of cyanobacterial biomass predicted to be present in surface waterblooms for 10-21 August 1983. The figure also illustrates how predictions about surface bloom formation are checked against the observation on NOAA images. The four different lines relate to four different geographical areas on the IJsselmeer grid, representing model output for the northern, western, southern, and southeastern areas of the lake (Fig. 1). Overall, there is a good match between surface bloom prediction and observation in Fig. 7. On 10, 11, 15, and 20 August, both the model and NOAA image indicate the absence of surface blooms. The model predicts surface blooms on 12, 14, 18, and 21 August. NOAA images are available for 18 and 21 August only, and here the prediction by the model is correct. A bloom that can be seen on the image of 19 August, however, is not reproduced by the model. The image on 15 August shows the absence of surface blooms, shortly after the model (correctly) predicts the disappearance of the bloom.

A similar analysis for all years yields the overall results for the validation, shown in Table 6. Surface blooms were observed on 23 images only; here the model gives a proper prediction in 19 cases $(83 \%)$. On 290 out of the 313 usable images, surface blooms are absent; the model gives a proper prediction in 270 cases $(93 \%)$. Overall, the model fails to predict four surface blooms, and predicts 20 extra blooms without support of observations on matching NOAA images. Also, 93 surface blooms are predicted when no NOAA image is available for validation through the presence of clouds. Cohen's kappa (e.g., Agresti 1996) provides a measure for the degree to which two judges (in our case NOAA image and model) concur in their respective sorting of $N$ items into $k$ mutually exclusive categories (in our case, bloom or no bloom present). Cohen's kappa for our data set of 313 images and matching predictions is $0.57 \pm 0.084$ (mean $\pm 1 \mathrm{SE}$ ). The lower limit of the $95 \%$ confidence interval is 0.41 , the upper limit 0.74 . Purely by chance, there would be no more than 2.87 cases of scum formation where model and observation would agree, whereas in reality model and observation 

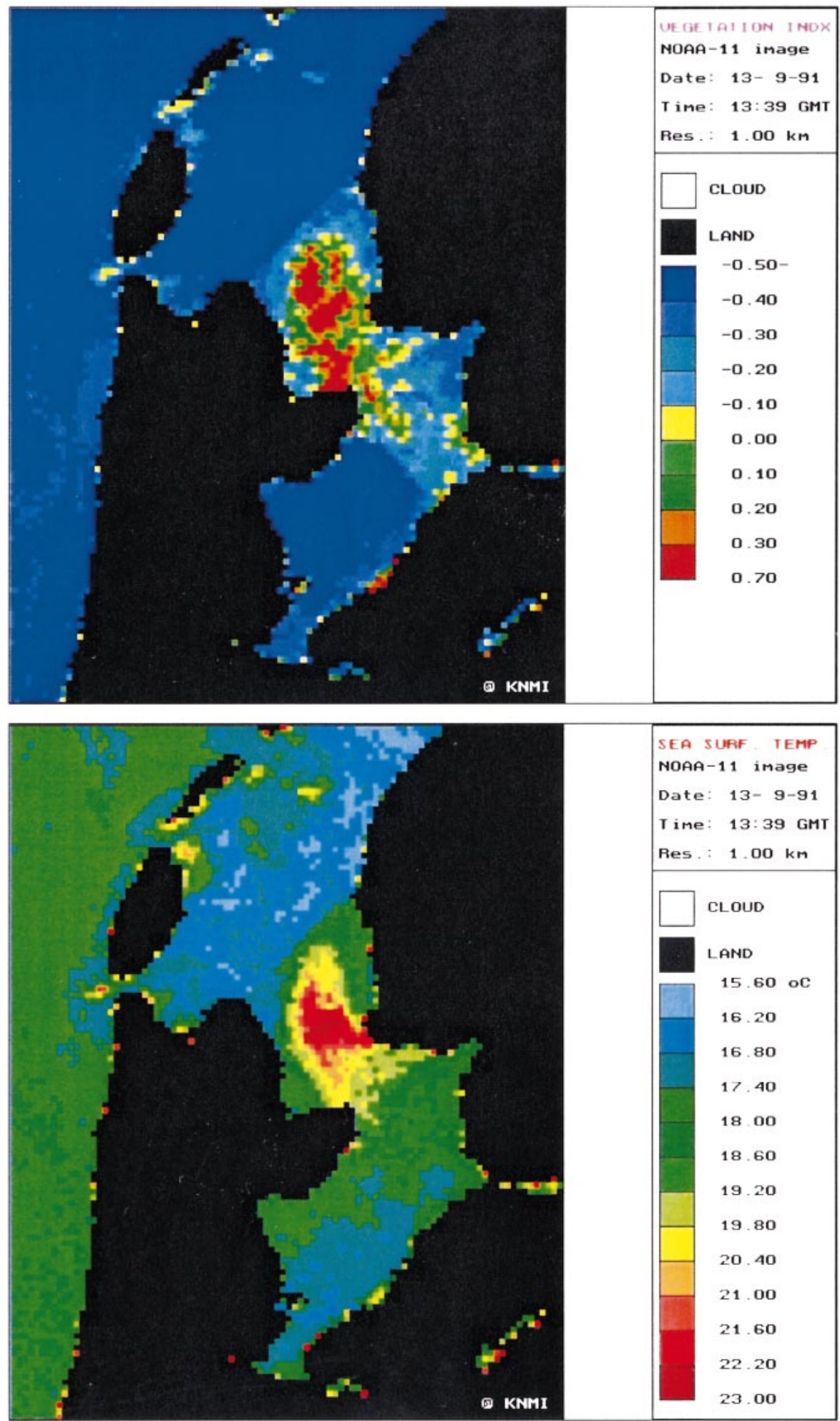

FIg. 4. NOAA-AVHRR image of the IJsselmeer on 21 August 1983. (Top) Normalized Vegetation Index (NVI); a positive value indicates the presence of a surface bloom. (Bottom) Lake surface water temperature; surface water temperature increases by strong sunlight absorption in surface blooms. The combination of NVI and surface water temperature can be used to detect the presence of surface blooms in the images. 


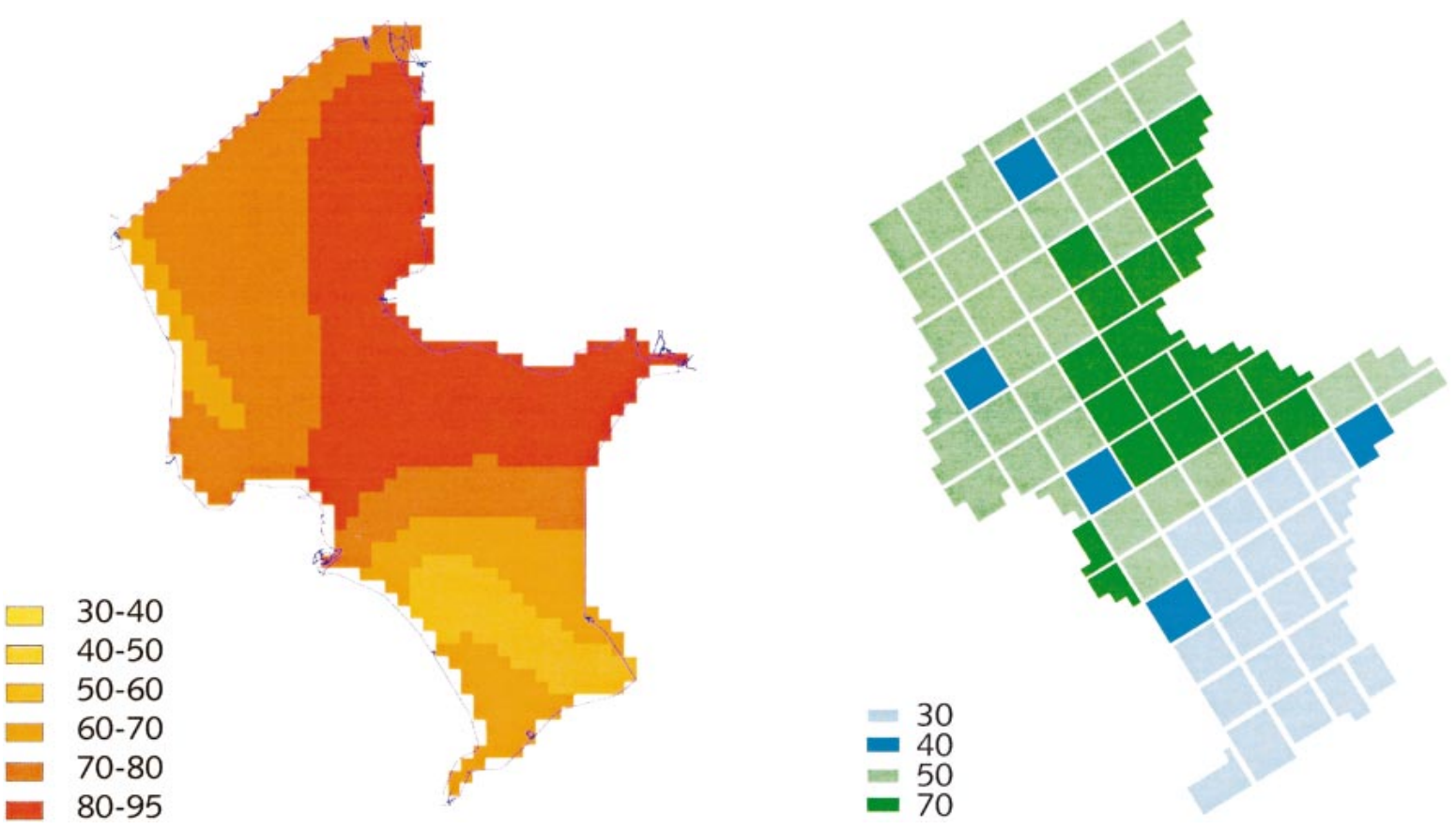

FIG. 5. Spatial distribution of chlorophyll $a$ (in $\mu \mathrm{g} / \mathrm{L}$ ) in the IJsselmeer. A comparison is shown between measurements on the left and model prediction (DBS) on the right. The left graph is based upon Kriging interpolation of the mean chlorophyll $a$ concentrations measured between 1972 and 1995 (April-September).

agreed in 19 cases. For the absence of surface blooms, where observation and model concur in 270 cases, the maximum agreement by chance would be 254 . Since surface bloom formation is a relatively rare event there is a high likelihood that a correct prediction of the absence of scums is purely based on chance. Predicting the presence of surface blooms correctly is much harder. However, for both types of predictions-absence and presence-the model performs (much) better than chance. If the model were to be used as an early warning system, it would be more serious to miss a bloom, than to (mistakenly) forecast additional blooms. Our model does not have a clear bias towards either predicting too few or too many blooms. If this were the case, adjusting the membership functions (i.e., calibration of the model, which we did not do) could have changed that.

\section{Mismatches between model and NOAA images}

On the four occasions were the model fails to predict a surface bloom, three of the cases reveal that the biomass of cyanobacteria as predicted by DBS was too low to yield surface blooms, although stability of the water column and buoyancy would have permitted bloom formation. On 3 September 1991, the model misses a small scum that is present in the area where the river IJssel enters the lake. At this location, DBS always predicts a low cyanobacterial biomass since the river water only has low numbers of cyanobacteria. On 19 August 1983 two NOAA images are available (see Fig. 7). On the morning of 19 August, the model cor- rectly predicts that the surface bloom of 18 August has disappeared; however, the return of a small bloom in the southwestern part of the lake (as can be seen on the NOAA image in the afternoon) is not reproduced by the model because the wind speed varied between 5 and $6 \mathrm{~m} / \mathrm{s}$. Surface bloom formation at these wind speeds is highly unlikely. However, using local windspeed data (measured on the dike separating IJsselmeer and Markermeer) we can see that wind speed dropped to $2.5 \mathrm{~m} / \mathrm{s}$ for a brief period in the afternoon, perhaps allowing surface bloom formation in the sheltered area behind the dike.

The prediction of additional blooms that were not seen on NOAA images may also be explained in various ways (again there is not one overall cause for the mismatches). Partially it may be the result of a too stern criterion for the NVI (surface blooms present only when NVI $>0$ ). Furthermore, in a proportion of the images that were deemed usable, not all of the lake was visible; small parts were covered by clouds. This increases the probability that regional scums produced by the model are missed by the satellite. The membership rule for wind speed governing the disappearance of existing blooms deviates somewhat from wind speeds given in literature (generally wind speeds exceeding 1-3 m/s; e.g., Wallace and Hamilton 2000) resulting in relatively resilient surface blooms in our model. Some of the bloom predictions without matching NOAA image disappear when this membership function for disappearance of blooms is adjusted-an option that is available to the end users of the model. 

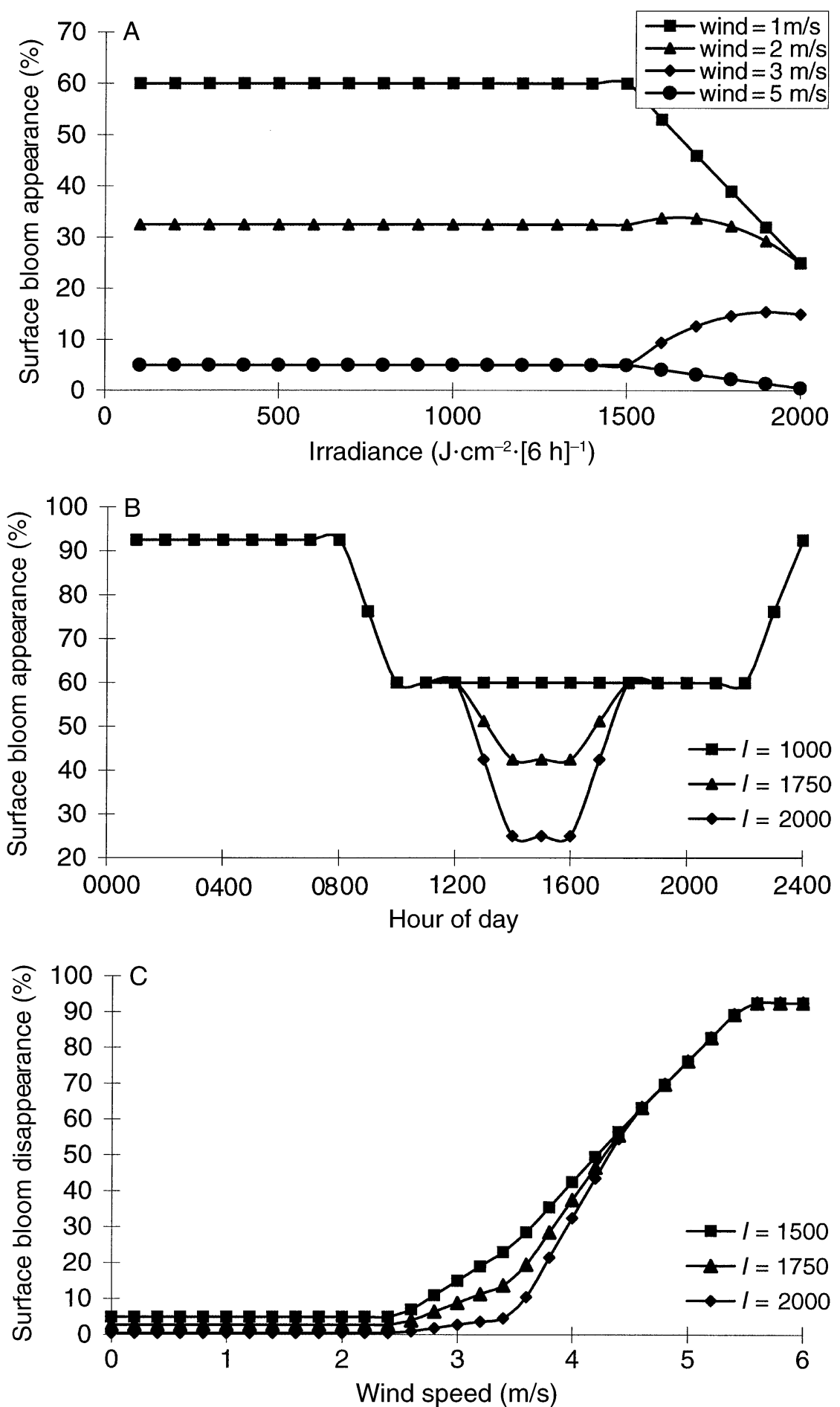

FIG. 6. Sensitivity analysis of the model predicting surface waterbloom formation. The degree of scum formation is shown to be dependent on the interaction between wind speed, cumulative irradiance, and time of day. (A) The degree of scum formation at 0800 hours as a function of wind speed and irradiance. (B) The degree of scum formation as a function of cumulative irradiance (in $\mathrm{J} \cdot \mathrm{cm}^{-2} \cdot[6 \mathrm{~h}]^{-1}$ ) and time of day and a fixed wind speed of $1 \mathrm{~m} / \mathrm{s}$. (C) The degree to which existing scums disappear as a function of wind speed and irradiance (at 0800 hours). 


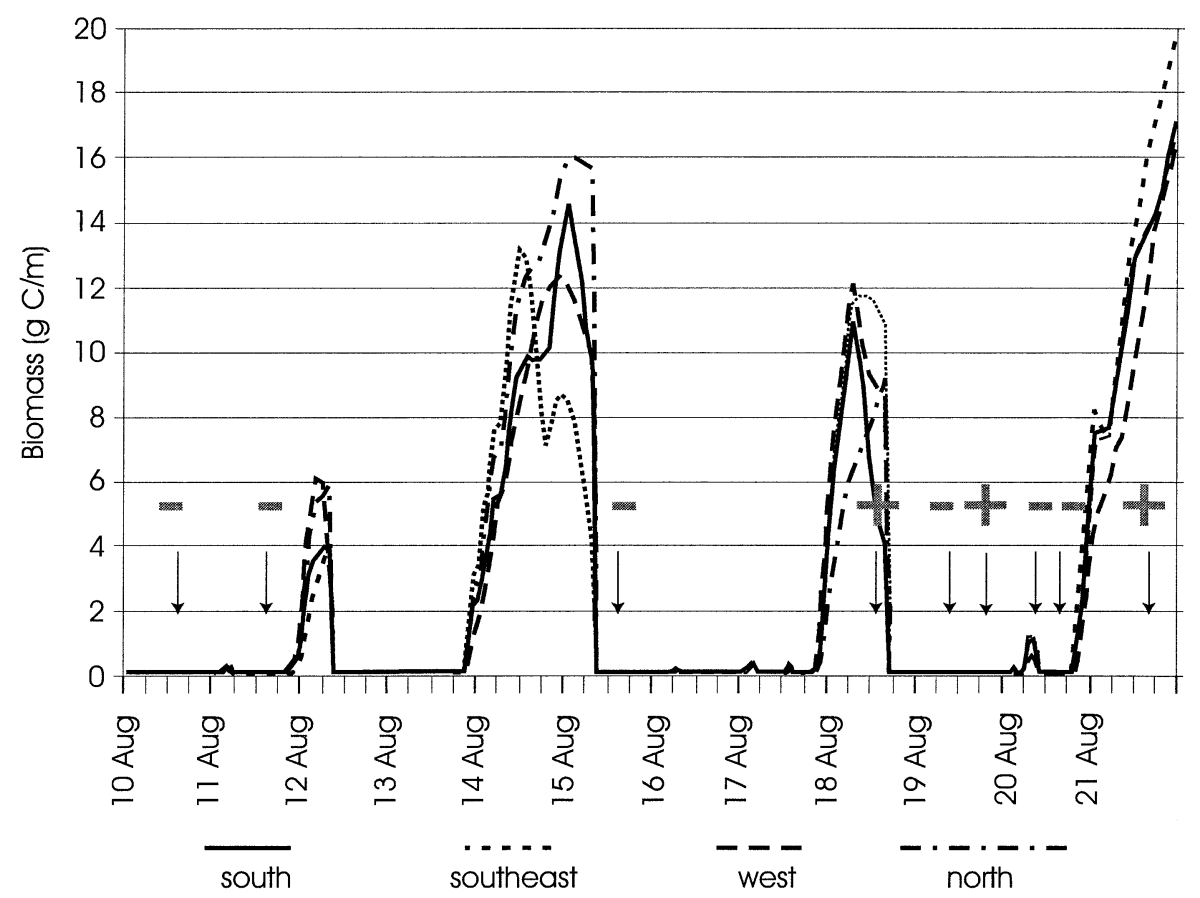

FIG. 7. Predicted cyanobacterial biomass present in surface waterblooms (g C/m², per hour and per grid cell) indicated by four lines for four different geographical areas of the IJsselmeer (see Fig. 1) during 10-21 August 1983. A plus or minus sign indicates that a NOAA image is available for that moment, showing presence (+) or absence (-) of surface blooms respectively.

These detailed examples show the large temporal and spatial dynamics in surface bloom formation and the accuracy that is required to predict surface blooms. Small (inevitable) errors in the model, in the processing of the NOAA images or using regional rather than local meteorological data all may cause discrepancies between images and model prediction. It is good to realize that a mismatch between model and observation in our study does not necessarily mean that the model output is wrong. Observation in this case is based upon satellite images. Radiance measured at the sensor is processed in a series of steps (see Prangsma and Roozekrans 1989) to get to the NVI or surface temperature that we used for validation of the model. Uncertainties are introduced at every step, for instance in the at-

TABLE 6. Validation on basis NOAA-AVHRR images of the IJsselmeer.

\begin{tabular}{lccc}
\hline \hline & \multicolumn{2}{c}{ NOAA } & \\
\cline { 2 - 3 } \multicolumn{1}{c}{ Model } & $\begin{array}{c}\text { Surface } \\
\text { bloom absent }\end{array}$ & $\begin{array}{c}\text { Surface } \\
\text { bloom present }\end{array}$ & Total \\
\hline Surface bloom absent & 270 & 4 & 274 \\
Surface bloom present & 20 & 19 & 39 \\
Total & 290 & 23 & 313 \\
\hline
\end{tabular}

Notes: Surface blooms were observed on 23 images; here the model gives a proper prediction in 19 cases $(83 \%)$. On 290 out of 313 images, surface blooms are absent; the model gives a proper prediction in 270 cases $(92 \%)$. The model fails to predict four surface blooms and predicts 20 extra blooms without support of observations. mospheric correction or in the algorithms that extract concentrations of chlorophyll from $R(0)^{-}$, the subsurface reflected irradiance. The same is true, however, for every type of observation or measurement that is used for model validation. Errors are introduced by sampling, sample storage, and in analysis-for instance in the estimation of the chlorophyll concentration.

\section{Risk analysis for the IJsselmeer}

Table 7 shows the result of a "risk analysis" for surface bloom formation in the IJsselmeer; it shows the number of hours the model predicts surface blooms in at least a part of the IJsselmeer. In total, surface blooms are predicted for $1913 \mathrm{~h}$ (or $5.4 \%$ of the time) during

TABLE 7. Number of hours during which cyanobacterial surface waterblooms are present in the IJsselmeer as predicted by the model for the years 1986-1996.

\begin{tabular}{lrrrrr}
\hline \hline Year & Jul & Aug & Sep & Oct & Total \\
\hline 1986 & 41 & 51 & 106 & 31 & 229 \\
1987 & 41 & 68 & 30 & 5 & 144 \\
1988 & 7 & 122 & 47 & 4 & 180 \\
1989 & 122 & 93 & 37 & 9 & 261 \\
1990 & 39 & 74 & 26 & 0 & 139 \\
1991 & 102 & 86 & 16 & 43 & 247 \\
1992 & 15 & 33 & 0 & 1 & 49 \\
1993 & 0 & 43 & 84 & 0 & 127 \\
1994 & 37 & 10 & 2 & 144 & 193 \\
1995 & 28 & 24 & 22 & 58 & 132 \\
1996 & 21 & 36 & 103 & 52 & 212 \\
Total & 453 & 640 & 175 & 347 & 1913 \\
\hline
\end{tabular}




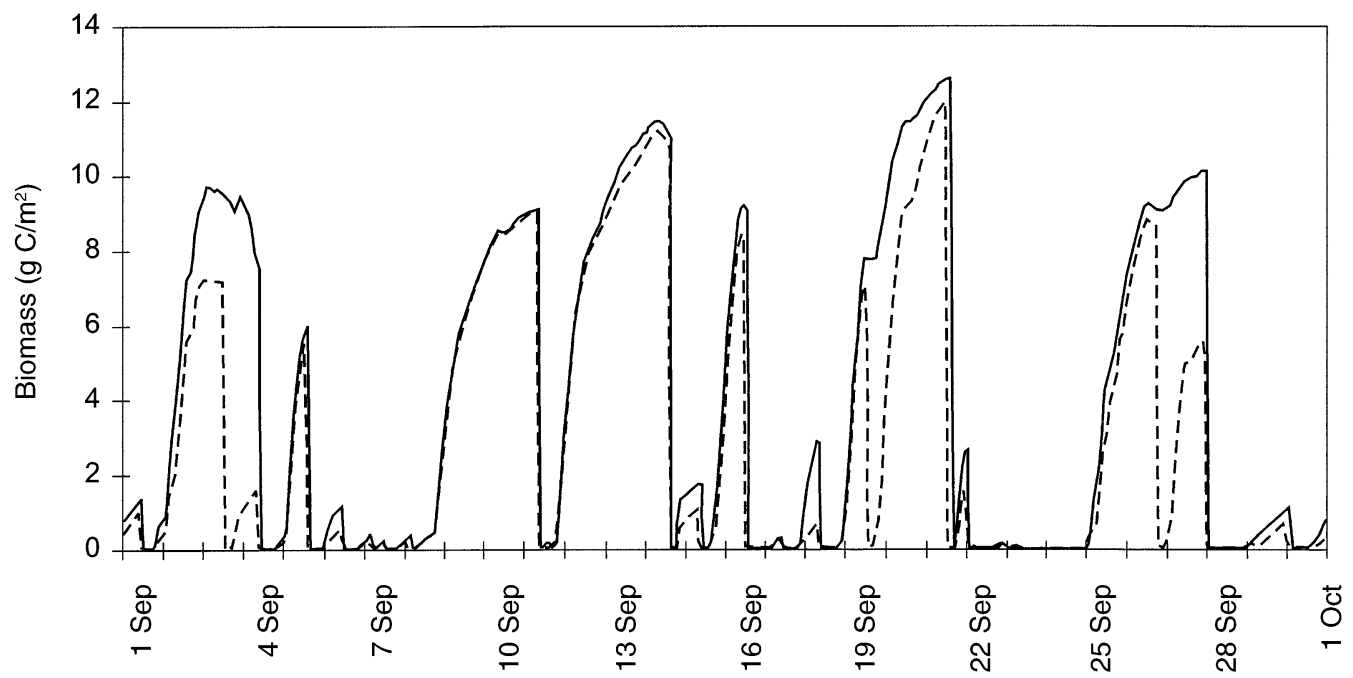

FIG. 8. Comparison of the model output for September 1991 between predictions based upon actual meteorological data (solid line) and simulated weather forecasts (dotted line) in which an uncertainty in wind speed of $\pm 0.4 \mathrm{~m} / \mathrm{s}$ is taken into account.

the 12 summers that we studied. Surface blooms are most prominent in August, a prediction that fits the population dynamics of bloom forming cyanobacteria, which appear rather late in the phytoplankton succession of the IJsselmeer. However, in some years, nuisance blooms of Microcystis appear rather early in the year, some of the highest concentrations of cyanobacterial toxins have already been measured in early July. Surface blooms are usually rare in October, when populations of cyanobacteria start to disappear, among other reasons, through a loss in buoyancy in response to a lower water temperature, resulting in an increase in carbohydrate ballast (Kromkamp et al. 1988, Visser et al. 1997). The year 1994 is an exception to this case, when weather conditions allowed extensive surface bloom formation even in October. NOAA images and the model show that especially northwestern and southeastern areas of the lake are prone to surface bloom formation. Despite a strong reduction in nutrient loading during the period we studied, there is no trend (yet) towards less surface bloom formation.

\section{Weather forecast}

The validation of the model was based upon the use of historical meteorological data. Prediction of blooms that would enable early warning would have to be based on a (long-term) weather forecast. Evidently, the uncertainty of the forecast increases with the duration of the outlook. For early warning against surface blooms, a period of some 72 hours seems to be sufficient. The most important meteorological factor affecting surface bloom formation is wind speed. Over the period considered, the uncertainty in the prediction of the wind speed is less than $0.5 \mathrm{~m} / \mathrm{s}$ (J. Scheur, personal communication). This uncertainty is determined by an uncertainty in the value of the wind speed itself, and in the timing (for instance the wind speed drops earlier than foreseen). To test the sensitivity of the model for uncertainties in the weather forecast, the output for 1983, 1989, and 1991 based upon actual meteorological data was compared to the output based upon "simulated" weather forecasts. In these simulated weather forecasts, a realistic measure of uncertainty was added to the meteorological data (wind speed $\pm 0.4 \mathrm{~m} / \mathrm{s}$ ). The results appeared not to be very sensitive to this limited uncertainty in wind speed (Fig. 8).

\section{Discussion}

We have presented a model that describes the formation of cyanobacterial surface waterblooms. Since blooms of toxic cyanobacteria are a global problem, we are not the first to present a cyanobacterial bloom model. However, where most models focus on either predicting the biomass (e.g., Bonnet and Poulin 2002, Howard and Easthope 2002) or the vertical distribution of cyanobacteria (e.g., Howard et al. 1996, Visser et al. 1997), we go one step further and actually predict the formation of surface blooms (scums) in time and space. Scum formation is at the heart of the problem. Two earlier studies, Sherman and Webster (1994) and Howard (2001) also modeled scum formation, but the first model is only validated on physical, not biological, aspects, whereas the second model is only validated in general terms. To the best of our knowledge, our model is the first to be validated on the basis of a (long-term) field data set. We have taken a, perhaps, unusual approach in combining two modeling techniques. We do not claim that this is the only valid, or even the best, approach. Rather we want to show that in the range of simple regression models to complex numerical models, our approach of combining an existing model for biomass with a fuzzy expert system for water column 
stability and buoyancy certainly has its merits. Fuzzy expert systems can be valuable tools, perhaps especially in ecology. In ecological studies, data sets are often incomplete and/or inaccurate. Fuzzy logic allows working with uncertainties and qualitative data. Expert knowledge may only be available in qualitative terms, rather than quantitatively. Uncertainties are crucial in the modeling and understanding of ecosystems. Hence Droessen (1996) sees fuzzy logic models not as a "weak" option, but rather as an ingenious way to deal with the inevitable uncertainties in ecology. Fuzzy models appear less prone to error propagation when compared to full mechanistic models working on the same problem. In this discussion, the focus will be on the fuzzy model, as the modeling of cyanobacterial biomass has been presented elsewhere (Van der Molen et al. 1994, Van der Molen 1999).

\section{Alternative model approaches}

In this study, we choose to model the appearance of algal surface blooms by means of fuzzy logic. We can think of two alternative modeling formats that could be used instead. First, we could have built a full mechanistic model of bloom formation based on differential equations. Or we could have chosen for a statistical (regression) model that simply describes the observed relation between the explanatory variables (biomass, wind, irradiation, time of the day) and the response variable (bloom formation). It is interesting to compare how these three formats (fuzzy logic, differential equations, statistical model) employ the existing data or require data that may not be available. The model based on fuzzy logic predicts algal blooms by combining the expert knowledge on bloom formation with available data on the explanatory variables. Since the data on the observation of blooms were not used for calibration of the model, they could rightfully be used for validating the model. This would not have been possible for a model based on differential equations. Many physical, chemical, and biological factors are involved in the initiation, the maintenance, and the demise of blooms (e.g., Paerl 1988). For many of these factors, good quality data from field research or experimental studies are missing. Recknagel (1997) stated that the application of dynamic, deductive, phytoplankton models still seems to be restricted by a lack of knowledge. The lack of accurate data is a general problem for full mechanistic models. To cope with the resulting error propagation it is therefore normal practice to calibrate such models on the response variables, in this case the presence of blooms. The fact that these data are used to calibrate the model make them unfit for model validation. Therefore, if these data are sparse, as is the case with scum formation, one would not be able to validate a model based on differential equations, whereas the step of validation seems a necessity for a model that aims at being used as an early warning system. A statistical model does not have the problem that a mechanistic model has of demanding information that is not available. But the regression equation that directly links the available information on explanatory and response variables would not fully exploit the available information because it would omit the expert knowledge on bloom formation. Moreover, although we had access to a 12-yr data set of NOAA images of the IJsselmeer, only 23 images actually showed surface waterblooms. Since statistical models are based on the reduction of large numbers of observations, a statistical approach was not favored. Also validation of the predictive power of the statistical model (as opposed to testing the significance of the explanatory variables) is problematic since we would again need a new independent data set to validate the fitted relations, whereas data on bloom formation are already sparse. We therefore conclude that the method based on fuzzy logic presented here fully exploits the available information (including expert information that otherwise remains inaccessible), does not demand data for calibration that are not available, is less prone to error propagation, and finally allows for a truly independent, and in our case successful, validation of the model.

\section{Credibility and acceptability of models}

Van der Molen (1999) distinguishes acceptability of models from credibility. For credibility, it is essential that the model goes through the procedure of system analysis and that uncertainties and limitations of the model are addressed (see next paragraphs). Whether the performance of the model is acceptable is best left to the end user of the model (Rykiel 1996). The result of a validation procedure is not so much general acceptance (or rejection) of the model, but rather that the model is tested for its suitability, taking the intended use of the model into account. In our case, the local water authorities accepted the model by expressing a keen interest in developing the model into a fully operational tool. In the list of validation procedures given by Rykiel (1996) our procedure would fit into "event validity," in which a comparison between the model and system is made for the occurrence, timing, and magnitude of simulated and actual events. The spatial distribution of surface blooms (magnitude) in our model is the result of (1) the gradient in cyanobacterial biomass that is observed in the lake and reproduced by DBS, (2) the lake bathymetry (for a buoyant colony it takes longer to reach the surface at a deep location), and (3) the movement of scums across the lake. Spatial variation in the thresholds for the appearance or disappearance of surface blooms is not included, i.e., these are uniform across the lake. If the output of the fuzzy model allows surface bloom formation (i.e., sufficiently stable water column and sufficiently buoyant cells), the model will actually predict surface blooms in any of the 85 grid cells where DBS computes sufficient cyanobacterial biomass. 


\section{System analytical approach}

System analysis is a logical and systematical approach wherein assumptions and criteria are clearly defined and specified (e.g., Beck 1997). Several stages are identified. During problem analysis, a general problem is specified and translated into objectives. These objectives are further specified in a conceptual framework that may be formalized into a set of mathematical equations, governed by parameters. A conceptual model should address the variables to be included in the model, relationships between these variables, a spatial schematization of the system, temporal aspects and the required input data. In the next phases, during sensitivity analysis, parameter estimation (often called calibration), and validation, the model is developed and adjusted to the specific circumstances of the system under consideration, using the available data. Finally, the model is applied. Although the system analytical approach was developed for the construction of more "traditional" fully mechanistic models, it provided a useful framework in developing the fuzzy model, although some small deviations occurred.

Our objective is to develop a model that predicts the occurrence of cyanobacterial surface waterblooms in the open water of a large lake. The conceptual framework describing surface waterbloom formation is given by the work of Reynolds and Walsby (1975), i.e., three factors must be considered by the model: cyanobacterial biomass, stability of the water column, and buoyancy. Hence, it was clear that wind-induced mixing in a nonstratified water column would prevent buoyant cyanobacteria from forming surface waterblooms. We needed a fairly detailed spatial schematization of the IJsselmeer, since we knew a priori that a gradient in the density of cyanobacteria exists in the lake, and that wind-driven transport carries blooms across the lake. Furthermore, we needed relatively short time intervals since surface waterbloom formation is a highly dynamic process. The model would need to take July through October into account, since surface blooms have been observed over the years during this period.

For the first condition given by Reynolds and Walsby (1975), biomass, the established water quality model DBS was used. Steps three to seven of the system analysis framework were followed in setting up this model and in its application to the lake (see Methods and Van der Molen [1999]). For the fuzzy modeling of the other two conditions - stability and buoyancy-steps three and five were omitted, and expert knowledge was formalized in membership functions and the resulting fuzzy model was applied to the IJsselmeer without further calibration. Calibration would have meant adjusting the membership functions, an option that we did not use since we felt that the original settings gave a good representation of the expert knowledge. A sensitivity analysis was carried out and the main results are presented in Fig. 6. Validation of the model output was carried out using a 12-yr data set of NOAAAVHRR images, which only delivered 23 occasions on which surface blooms were discernable. In applications of the model, the timing and location of surface waterbloom formation was studied, yielding a risk analysis for the IJsselmeer, and the usefulness of the model as an early warning system was tested.

\section{Early warning - are there alternatives for models?}

Current lake monitoring programs for algal blooms are reactive and provide insufficient means for advance warning (Schofield et al. 1999). Sorrano (1997) found that no single physical, meteorological, or limnological factor indicates that bloom formation is imminent. For instance, no relationship between epilimnetic chlorophyll levels and the occurrence of surface scums was found. It seems inevitable to use models, taking meteorological factors into account, as we have done in our study. Remote sensing however may have the potential to yield an early warning. This would be the case if blooms could be detected in their very early stages. Schofield et al. (1999) are doubtful, however about the potential of remote sensing in detecting low numbers of a nuisance species against a background of general phytoplankton.

In situ samples of spatially heterogeneous parameters like total suspended matter, chlorophyll $a$, light extinction coefficients and Secchi depth are often not representative for the spatial mean of these parameters (Dekker et al. 2001). Hence, the spatial patterns cannot be represented using traditional in situ sampling techniques. The NOAA data set used for validation in our study certainly has its limitations, but it is the only viable alternative to trace the presence of surface scums in a large lake over a longer period. Given the discussion above about uncertainties in model and satellite imaging, the key question remains: How valid are the model predictions? Following Rykiels' (1996) guidelines, this question becomes: are the predictions of surface waterbloom formation useful in a practical sense? What are the limitations of the current model?

\section{Limitations of the model}

The model has been tested only on the large lake IJsselmeer. We can not formally say whether it would perform equally well in other lakes. However, the fuzzy part of the model is based upon expert knowledge of the ecology of bloom forming cyanobacteria. This knowledge is based upon studies of many lakes, and should be universally applicable. The DBS model that yields cyanobacterial biomass has been applied to many more systems than just the IJsselmeer. The algal module in DBS-Bloom calculates the dynamics of algae and cyanobacteria assuming fully mixed conditions, i.e., vertical migration of cyanobacteria is not included. This is a clear shortcoming of DBS. Even if the fuzzy model takes care of the role of buoyancy in surface bloom formation, buoyancy is also important 
in growth and the loss processes of cyanobacteria. It is an aspect where the modeling of cyanobacterial biomass could be improved.

Surface blooms were predicted in the IJsselmeer during $5.4 \%$ of the time only. This may seem surprisingly rare given the bad reputation of cyanobacterial scums. Soranno (1997), in a study of Lake Mendota, found a similar (low) frequency of scum formation in the open water (10 days during summer). However, the model presented by us does not cover the more persistent scums of cyanobacteria that are often present in sheltered places like harbors and sluices. These shoreline scums determine the public perception of the problem. Persistent scums often start out as less dense blooms in the open water, but are driven to the leeward shore by light winds. It is not particularly difficult to extend the fuzzy model so that it would include persistent scums in sheltered locations. Almost all that would be required is to adjust the membership functions on the basis of the existing expert knowledge. The reason we have not done it (yet) is that we were unable to find data for validation of this model. Pixels of remote sensing images at the land-water interface cannot be used, and interviews in yachting marinas, etc., did not yield sufficient information about the occurrence of scums.

Although the acceptable match between model and observation (Kappa of $0.57 \pm 0.084$ ) shows that the model has the capacity to be used as a fully operational model, some adjustment would still be needed (in addition to addressing the issue of more permanent blooms). In the current setting-with DBS providing algal biomass-online models for hydrology, water chemistry, meteorology, and biology would be needed. The fuzzy module is easy to convert into an online version for operational application. Continuous updates on the weather forecast would be needed. A new generation of satellite sensors (e.g., MERIS on board ENVISAT), are better suited to monitor algae. Ideally, reflectance spectra provided by a number of sensors would be processed automatically into maps of chlorophyll and cyanobacteria. A close coupling between the model and the images could provide a continuous validation process.

\section{ACKNOWLEDGMENTS}

This study was supported by grants from RWS-Meetstrategie $2000+$, RWS-RDIJ, and Delft Hydraulics. We are grateful to Bruce Michielsen and Marinus Bokhorst for their involvement in earlier versions of the fuzzy model. We acknowledge Hans Roozekrans, Hendrik Buiteveld, Paul Boers, Eddy Lammens, Anouk Blauw, and two anonymous referees for constructive comments during various stages of the study. Eddy Lammens provided the data for Fig. 5. David Dunlop corrected the English.

\section{Literature Cited}

Agresti, A. 1996. An introduction to categorical data analysis. John Wiley and Sons, New York, New York, USA.

Beck, M. B. 1997. Applying systems analysis in managing the water environment: towards a new agenda. Water Science and Technology 36:1-17.
Bonnet, M. P., and M. Poulin. 2002. Numerical modeling of the planktonic succession in a nutrient-rich reservoir: environmental and physiological factors leading to Mircocystis aeruginosa dominance. Ecological Modeling 156: 93-112.

Buiteveld, H. 1995. A model for diffuse light attenuation (PAR) and Secchi depth. Netherlands Journal of Aquatic Ecology 29:55-65.

Chorus, I., I. R. Falconer, H. J. Salas, and J. Bartram. 2000. Health risks caused by freshwater cyanobacteria in recreational waters. Journal of Toxicology and Environmental Health Part B-Critical Reviews 3:323-347.

Dekker, A. G., R. J. Vos, and S. W. M. Peters. 2001. Comparison of remote sensing data, model results and in situ data for total suspended matter (TSM) in the southern Frisian lakes. The Science of the Total Environment 268:197214.

Droessen, W. 1996. Formalization of ecological expert knowledge-based model of annual production of skylarks. Ecological Modeling 85:75-81.

Ecological Modeling. 1996. Special Issue. Ecological Modeling 85.

Howard, A. 2001. Modeling movement patterns of the cyanobacterium, Microcystis. Ecological Applications 11: 304-310.

Howard, A., and M. P. Easthope. 2002. Application of a model to predict cyanobacterial growth patterns to climate change at Farmoor Reservoir, Oxfordshire, UK. The Science of the Total Environment 282-283:459-469.

Howard, A., A. E. Irish, and C. S. Reynolds. 1996. A new simulation of cyanobacterial underwater movement (SCUM'96). Journal of Plankton Research 18:1375-1385.

Huisman, J., P. van Oostveen, and F. J. Weissing. 1999. Species dynamics in phytoplankton blooms: incomplete mixing and competition for light. American Naturalist 154:46-68.

Humphries, S. E., and V. D. Lyne. 1988. Cyanophyte blooms-the role of cell buoyancy. Limnology and Oceanography 33:79-91.

Ibelings, B. W., B. M. A. Kroon, and L. R. Mur. 1994. Acclimation of photosystem-II in a cyanobacterium and a eukaryotic green-alga to high and fluctuating photosynthetic photon flux densities, simulating light regimes induced by mixing in lakes. New Phytologist 128:407-424.

Ibelings, B. W., and S. C. Maberly. 1998. Photoinhibition and the availability of inorganic carbon restrict photosynthesis by surface blooms of cyanobacteria. Limnology and Oceanography 43:408-419.

Ibelings, B. W., L. R. Mur, and A. E. Walsby. 1991. Diurnal changes in buoyancy and vertical distribution in populations of Microcystis in two shallow lakes. Journal of Plankton Research 13:419-436.

Kahru, M., J. Markku Leppänen, and O. Rud. 1994. Cyanobacterial blooms cause heating of the sea surface. Marine Ecology Progress Series 101:1-7.

Kromkamp, J., J. Botterweg, and L. R. Mur. 1988. Buoyancy regulation in Microcystis aeruginosa grown at different temperatures. FEMS Microbiology Ecology 53:231-237.

Lammens, E. 1999. The foodweb of the IJsselmeer. Fieldata, hypotheses, models and scenarios. RIZA report 99. Cabri B.V., Lelystad, The Netherlands.

Middelkoop, H., and M. Van der Perk. 1998. Modelling spatial patterns of overbank sedimentation on embanked floodplains. Geografiska Annaler Series A, Physical Geography 80A:95-109.

Mitrovic, S. M., L. C. Bowling, and R. T. Buckney. 2001. Vertical disentrainment of Anabaena circinalis in the turbid, freshwater Darling River, Australia: quantifying potential benefits from buoyancy. Journal of Plankton Research 23:47-55. 
Paerl, H. W. 1988. Nuisance phytoplankton blooms in coastal, estuarine and inland waters. Limnology and Oceanography 33:823-847.

Prangsma, G. J., and J. N. Roozekrans. 1989. Using NOAA AVHRR imagery in assessing water quality parameters. International Journal of Remote Sensing 10:811-818.

Recknagel, F. 1997. ANNA-Artificial Neural Network model for predicting species abundance and succession of bluegreen algae. Hydrobiologia 349:47-57.

Reynolds, C. S. 1987. Cyanobacterial waterblooms. Advances in Botanical Research 13:67-143.

Reynolds, C. S., and A. E. Walsby. 1975. Water blooms. Biological Reviews 50:437-481.

Rykiel, E. J. 1996. Testing ecological models: the meaning of validation. Ecological Modeling 90:229-244.

Schofield, O., J. Grzymski, and W. P. Bissett. 1999. Optical monitoring and forecasting systems for harmful algal blooms: possibility or pipe dream? Journal of Phycology 35: $1477-1496$.

Sherman, B. S., and I. T. Webster. 1994. A model for the light limited growth of buoyant phytoplankton in a shallow, turbid waterbody. Australian Journal of Marine and Freshwater Research 45:847-862.

Soranno, P. A. 1997. Factors affecting the timing of surface scums and epilimnetic blooms of blue-green algae in a eutrophic lake. Canadian Journal of Fisheries and Aquatic Sciences 54:1965-1975.

Stelling, G. S. 1984. On the construction of computational methods for shallow water flow problems. Dissertation. Technical University, Delft, The Netherlands.

Van der Molen, D. T. 1999. The role of eutrophication models in water management. Thesis. Agricultural University, Wageningen, The Netherlands.
Van der Molen, D. T., F. J. Los, L. Van Ballegooijen, and M. P. Van der Vat. 1994. Mathematical modeling as a tool for management in eutrophication control of shallow lakes. Hydrobiologia 275/276:479-492.

Van der Molen, D. T., and R. Portielje. 1994. Multi-lake studies in The Netherlands: trends in eutrophication. Hydrobiologia 408/409:359-365.

Visser, P. M., B. W. Ibelings, and L. R. Mur. 1997. Autumnal sedimentation of Microcystis spp. as result of an increase in carbohydrate ballast at reduced temperature. Journal of Plankton Research 17:919-933.

Visser, P. M., B. W. Ibelings, and B. Van der Veer. 1996. Artificial mixing prevents nuisance blooms of the cyanobacterium Microcystis in Lake Nieuwe Meer, The Netherlands. Freshwater Biology 36:435-450.

Von Altrock, C. 1995. Fuzzy logic and neuro fuzzy applications explained. Prentice Hall, Upper Saddle River, New Jersey, USA.

Wallace, B. B., and D. P. Hamilton. 2000. Simulation of water-bloom formation in the cyanobacterium Microcystis aeruginosa. Journal of Plankton Research 22:1127-1138.

Walsby, A. E. 1994. Gas vesicles. Microbiological Reviews 58:94-144.

Walsby, A. E., P. K. Hayes, and R. Boje. 1997. The selective advantage of buoyancy provided by gas vesicles for planktonic cyanobacteria in the Baltic Sea. New Phytologist 136: 407-417.

Walsby, A. E., R. Kinsman, and B. W. Ibelings. 1991. Highly buoyant colonies of the cyanobacterium Anabaena lemmermannii form persistent surface waterblooms. Archiv fuer Hydrobiologie 121:261-280.

Webster, I. T., and P. A. Hutchinson. 1994. Effect of wind on the distribution of phytoplankton cells in lakes revisited. Limnology and Oceanography 39:365-373. 